\title{
Tones and traits - experiments of text-based extractions with cognitive services
}

\author{
Ulla Gain, Virpi Hotti
}

School of Computing, University of Eastern Finland, Kuopio, Finland

Ulla Gain, School of Computing, University of Eastern Finland, FI-70211, Kuopio, FINLAND. Email: gain@uef.fi

\begin{abstract}
Cognitive services mimic brain mechanisms by the algorithms, for example, extracting emotions, language styles, and social tendencies from text. The cognitive services offer the inferred insights that are even more detailed than the observation-based ground-truth data. In this paper, the text-based extractions are utilized by the cognitive services (i.e., Microsoft's Text Analytics and IBM's AlchemyLanguage, Natural Language Understanding, Personality Insights and Tone Analyzer). The tones (i.e., emotions, language styles and social tendencies) and personality traits (i.e., social tendencies, needs and values) are extracted from a web-site document with no time by the cognitive services the algorithmic functionality of which are exemplified. Both the tones and personality traits are the inferred insights that can be used to assess the personality. Finally, 47 personality traits are tabulated to illustrate the trait-based questions that can be used in the interventions.
\end{abstract}

Keywords: algorithms, cognitive function, personality assessment

\section{Introduction}

There are dozens cognitive services (i.e., cognitive building blocks) that can be used to illustrate the automation capabilities. We already use the cognitive building blocks even without thinking that they are cognitive ones. For example, we dictate to iPhone and it converts the speech into a text. However, when we examine the cognitive services more precisely, we will realize that language, speech and vision are the main cognized domains of the services. For example, IBM has divided their cognitive services into four groups (i.e., language, speech, vision and data insights) [1], whereas, Microsoft divides their cognitive services into five groups (language, speech, vision, knowledge and search) [2].

When we want to get the objective, or inferred, insights from the unstructured data of different kind (e.g., au- dio, images, text and video) then we need the cognitive services. The cognitive services give us the capabilities to get insights that are more objective. However, it has been found that the characteristics (e.g., personality traits) inferred from text can reliably predict a variety of real-world behavior [3]. Therefore, for example, the IBM Watson Personality Insights service provides a list of the behaviors (e.g., preferences [4]) that the personality is likely (e.g., treat yourself) or unlikely (e.g., put health at risk) to manifest.

It was the dream (e.g., "uncover the "information nuggets" [5], "digging into the data . . . to find out relevant items of the data" [6] or make the rule-based content categorization [7]) to get something useful from text cognitively until the IBM Watson Personality Insights service manifests with the text-based personality insights [8]. For example, the healthcare utilizations of 
the personality insights may differ from self-study to personalized services [8] (e.g., matching individuals such as doctor patient matching because patients prefer doctors who are similar to themselves, monitoring and predicting mental health such as predicting postpartum and other forms of depression from social media [9]). During the research of the cognitive services, we found only two services the extractions of which concern the social tendencies $[10,11]$. Hence, we found, for example, the global online platform called Talkspace that uses the Personality Insights "to better match users with therapists in their network using a self-learning system that seeks to better understand the traits of individual" and the platform "allows users to chat with a licensed therapist confidentially and anonymously" [12].

The personality traits (e.g., extraversion and openness) are heritable and associated with the behavioral outcomes. For example, extraversion is associated with "psychosocial, lifestyle and health outcomes such as academic and job performance, well-being, obesity, substance use, physical activity, bipolar disorder, borderline personality disorder, Alzheimer's disease, and longevity" [13].

In this paper, we report the experiments of the textbased extractions including the tones (i.e., emotions, language styles and social tendencies) and traits (i.e., social tendencies and their facets, needs and values). One of our main aims is to find out the argumentations for the extractions. Therefore, we construct the workflow for value propositions as an orchestrated attempt by the cognitive services the outcomes of which manifest the behavioral outcomes or help to revise the language styles.

\section{Material and methods}

The cognitive services can constitute a flexible building block assemblage. There are only two cognitive services (i.e., IBM Tone Analyzer and Personality Insights) to extract the social tendencies. Personality characteristics (i.e., social tendencies, needs and values) based on an open vocabulary approach. The input text is tokenized and transformed to a representation in a $\mathrm{n}$-dimensional space, and the service use an open source word embedding technique called GloVe to obtain a vector representation for the words in the input text [10].

Sometimes the web pages that have many advertisements might contain the crucial arguments, especially, when the new technology is adapted. In this paper, we used the URL of the Togaf 9.1. Content Metamodel [14] the content of which is used to exemplify the extractions of a different kind (i.e., emotions, language styles, social tendencies, needs and values), as well as, to illustrate the outcomes of the cognitive services with minimum human interventions.

First, we combined the cognitive services of two providers (i.e., IBM and Microsoft). However, the demonstration of the Microsoft Text Analytics API [15] did not summarize the key phrases without text manipulations (i.e., the human intervention is needed). Therefore, the Text Analytics service is excluded from our final construction (Figure 1). The detailed workflow of the utilized cognitive services is the follows:

- $\quad$ IBM AlchemyLanguage - Paste URL, Select Text Extraction, Copy text

- $\quad$ IBM Tone Analyzer - Paste Your own text, Click Analyze, Identify sentences with stronger tones in context or sorted by score

- $\quad$ IBM Personality Insights - Paste Your own text, Click Analyze, Identify personality traits (i.e., social tendencies / personality types and their facets, need, and values). 


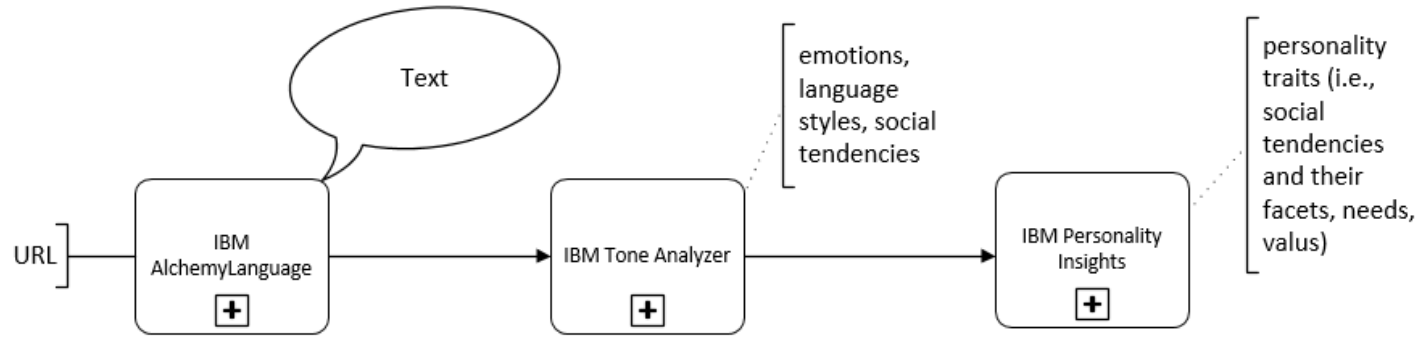

Figure 1. Construction for text extraction (drawn by Microsoft Vision).

Finally, we will try to explain the results of the extractions. When we tried to formalize the relationships between traits and summaries, we found that there is no mathematical relationship exists, for example, between "the percentiles reported for Big Five dimensions and facets" [16]. Therefore, it is impossible to compare whether the cognitive services offer the even more detailed explanations of the calculated results than the results of the on-line personality questionnaires based on a public domain collection of the IPIP items for use in personality tests. The International Personality Item Pool (IPIP) offers, for example, 50 personality questions the calculation of which is explained [17] (Appendix 1).

The IPIP questions illustrate the simplicity of the personality questionnaires whereas the explanations of the traits are complex ones. Therefore, we try to form the trait-based questions to support, for example, the traitbased intervention. We use the IBM Natural Language Understanding service [18] to extract the semantic roles (i.e., subject, action and object) of the sentences (i.e., the explanations of the traits). We use the semantic roles to exemplify the trait-based personality questionnaire as follows (Figure 2 ):
- IF the action is are THEN the question starts by Am (see the rule 1)

- IF the object contains your THEN the question contains my (see the rule 1 )

- IF ahead of the action there is the expression or term THEN it will be included in the question (see the rule 2)

- IF ahead of the action there is are THEN it will be included in the question (see the rule 3 and the rule 4)

- IF the sentence contains yourself THEN the question contains myself (see the rule 4 )

- IF the sentence contains two or more actions THEN the question starts by the first action (see the rule 5)

- IF the sentence contain two or more you THEN the meaning of the sentence affects the replacements (i.e., me, I or I am if there is your are). 


$$
\text { "You carefully think through decisions before making them". }
$$

2)

"You carefully think through decisions before making them "
making them

3)

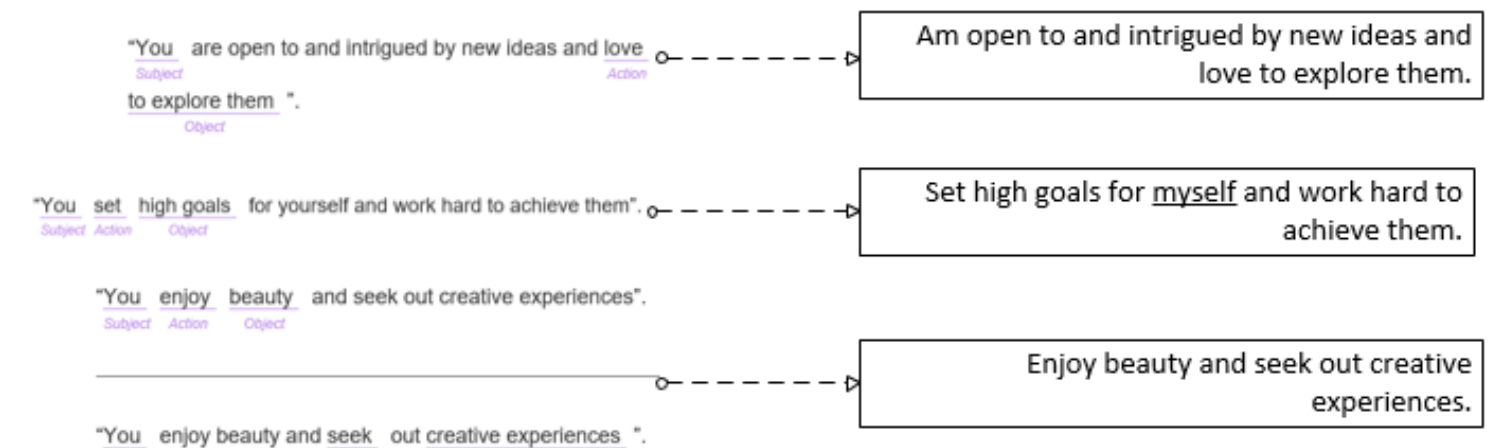

5)

"You enjoy beauty and seek out creative experiences .

"You feel

you have the ability to succeed in the tasks you set out to do ".

6)

You feel you have the ability to succeed in the tasks you set out to
I set out to do.
do".

"You feel you have the ability to succeed in the tasks you set out to do:

Figure 2. Rules of the trait-based questions (drawn by Microsoft Vision).

If the trade-based questions are answered in scoring from zero to one hundred (i.e., zero percent correspond to the trait that does not exist and one hundred the opposite to it) then the straight comparability of results remains (i.e., between the results scores of the IBM Personality Insights and the answers of the trade-based questions).

\section{Results}

The Tone Analyzer service produces the tones (i.e., emotions, language styles and social tendencies) at the document (Figure 3). The tone scores indicate the probability of the tones. The emotion tones are anger, disgust, fear, joy and sadness. The language tone describes the writing style the categories of which are analytical, confident and tentative. The social tones (openness, conscientiousness, extraversion, agreeableness and emotional range) are adapted from the bigfive personality model. 

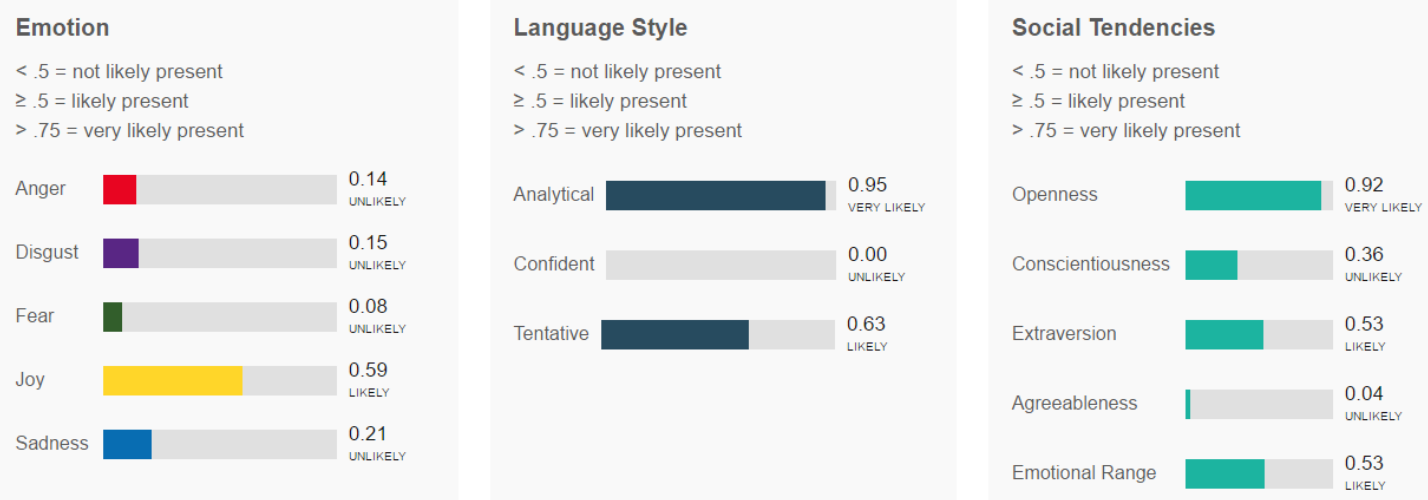

Figure 3. Tones at the document level.

The sentences are highlighted color-based by the selected tone (Figure 4). Furthermore, it is possible to revise the tones of the sentences in context or ranked by the score. The limits of the scores are observable (i.e., < $5 \%$, $5-75 \%$ or > $75 \%$ ) [19]. The model includes five primary dimensions (i.e., social tendencies) as follows [20]:

- Openness "is the extent to which a person is open to experiencing a variety of activities",
- Conscientiousness "is a person's tendency to act in an organized or thoughtful way",

- Extraversion "is a person's tendency to seek stimulation in the company of others",

- Agreeableness "is a person's tendency to be compassionate and cooperative toward others",

- Emotional Range, "also referred to as Neuroticism or Natural Reactions, is the extent to which a person's emotions are sensitive to the person's environment".

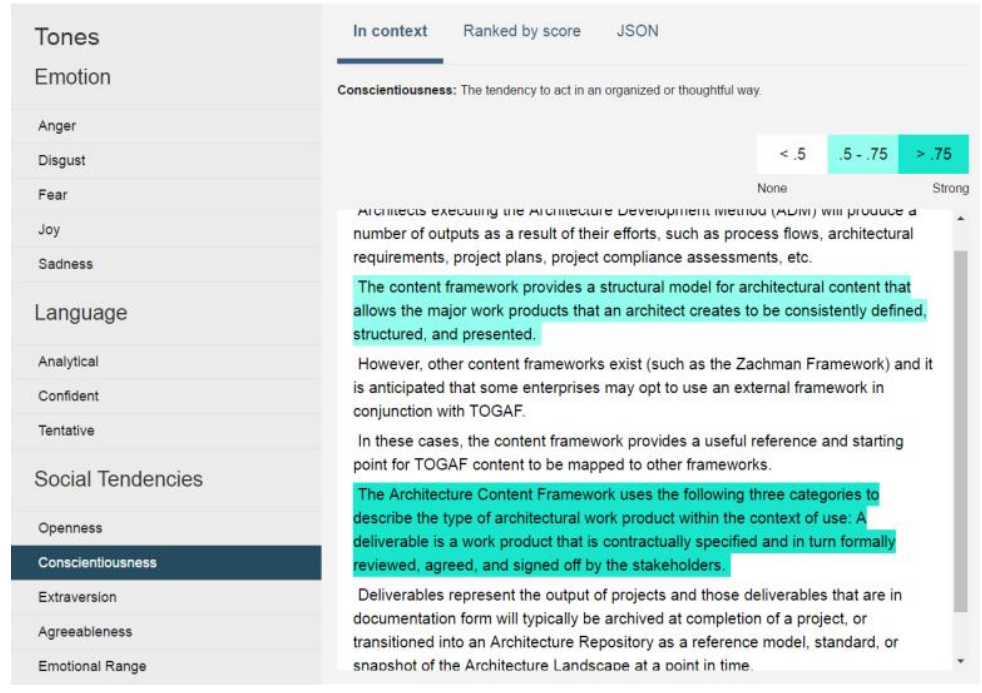

Figure 4. Tones at the sentence level. 


\section{Summary}

\begin{tabular}{|l}
\hline $\begin{array}{l}\text { Primary and secondary } \\
\text { dimensions }\end{array}$ \\
You are shrewd and somewhat critical. \\
traditional values to help bring about positive changes. You are \\
philosophical: you are open to and intrigued by new ideas and love to \\
explore them. And you are proud: you hold yourself in high regard, \\
satisfied with who you are. \\
Your choices are driven by a desire for discovery. \\
You are relatively unconcerned with both tradition and taking pleasure in \\
life. You care more about making your own path than following what \\
others have done. And you prefer activities with a purpose greater than \\
just personal enjoyment.
\end{tabular}

Figure 5. Example of summary from the IBM Personality Insights service.

The Personality Insights service generates the summary (Figure 5) and sunburst from the inferred personality traits. Furthermore, it gives the short descriptions for the traits. However, we do not use them because they do not explain the high or low scores of the traits.

The primary and secondary dimensions affect the first sentence of the summary (i.e., the first paragraph) [21]. The second paragraph of the summary is generated using the three main facets of the primary dimensions [22]. However, it is not explained explicitly how the certain adjectives (i.e., shrewd and critical) of the first sentence and the statements of the second paragraph are selected.

There are 60 explanations for 30 facets (i.e., traits) of five dimensions and we tabulated them (Appendix 2) by following the traits in the sunburst (Figure 6). Furthermore, we have use the table to highlights the textbased trait finding because each of them can be evaluated separately.

We did not find out the explanations of the summary for the traits of the need (the 3rd paragraph of the summary) and values (the 4th paragraph of the summary). However, we tabulate the found definitions of the needs and values. The needs of the author (Table 1) resonate the aspects of the products or services. The values describe the human's (or the author's) motivating factors that influence decision-making. There are only explanations for high values (Table 2). Furthermore, we found only one research [23] in where two traits are mapped explicitly the behavioral outcomes, and the research results are statistically significant. 


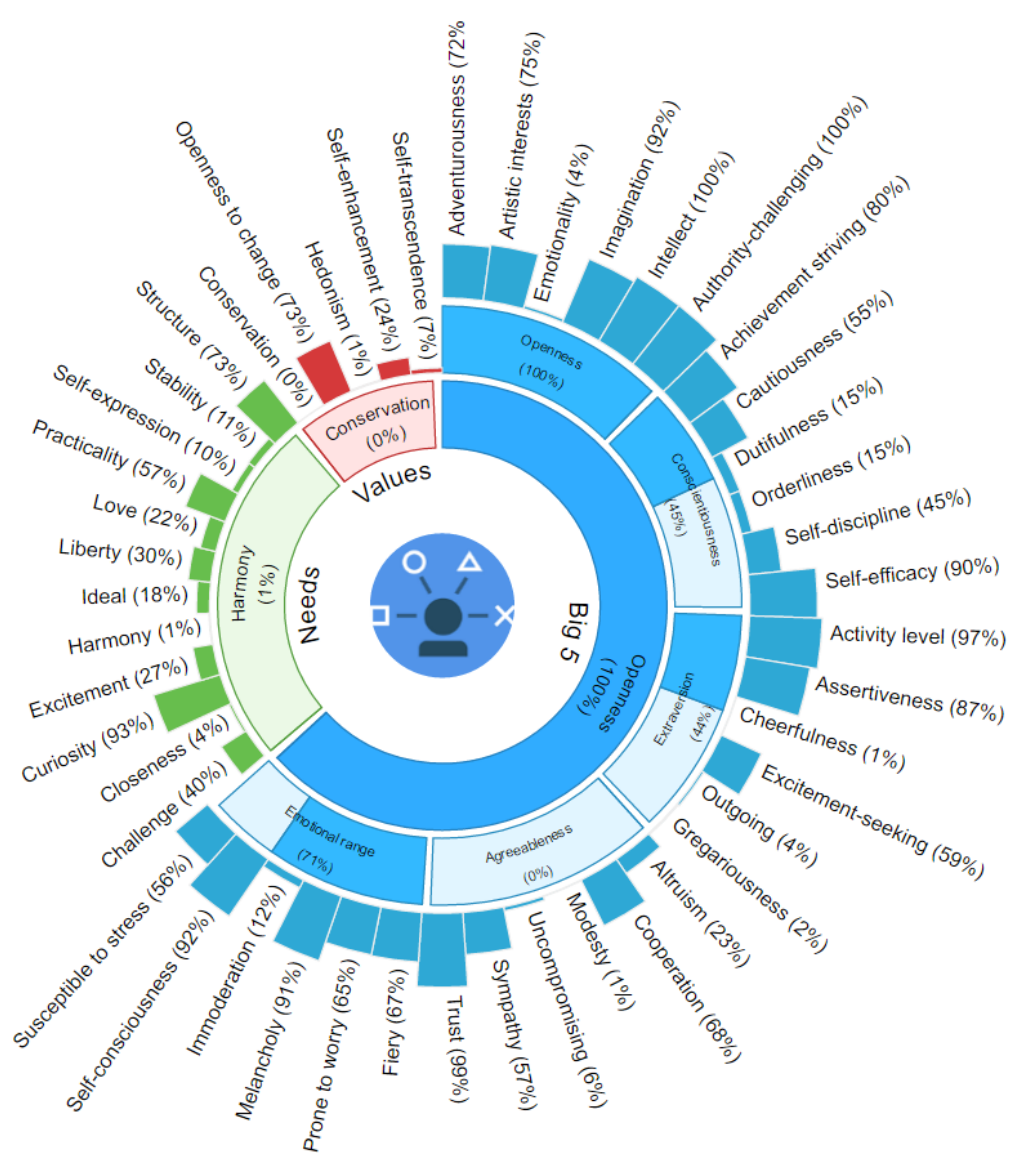

Figure 6. Example of the sunburst generated by the IBM Watson Personality Insight service [10].

Table 1. Example of the needs the definitions of which are adapted [24].

\begin{tabular}{ll}
\hline Trait & High definitions \\
\hline Challenge & "Have an urge to achieve, to succeed, and to take on challenges" \\
Closeness & "Relish being connected to family and setting up a home" \\
Curiosity & "Have a desire to discover, find out, and grow" \\
Excitement & "Want to get out there and live life, have upbeat emotions, and want to have fun" \\
Harmony & "Appreciate other people, their viewpoints, and their feelings" \\
Ideal & "Desire perfection and a sense of community" \\
Liberty & "Have a desire for fashion and new things, as well as the need for escape" \\
Love & "Enjoy social contact, whether one-to-one or one-to-many. Any brand that is involved in bringing people \\
& together taps this need" \\
Practicality & "Have a desire to get the job done, a desire for skill and efficiency, which can include physical expression \\
& and experience" \\
Self-expression & "Enjoy discovering and asserting ... own identities" \\
Stability & "Seek equivalence in the physical world ... favor the sensible, the tried and tested" \\
Structure & "Exhibit groundedness and a desire to hold things together ... need things to be well organized and under \\
& control"
\end{tabular}


Table 2. Example of the values the definitions of which are adapted [25].

\begin{tabular}{lll}
\hline Trait & High definitions & Examples of behavioral outcomes \\
\hline Conservation & "Emphasize self-restriction, order, and resistance to change" & \\
Openness to change & "Emphasize independent action, thought, and feeling, as & \\
& $\begin{array}{l}\text { well as a readiness for new experiences" } \\
\text { Hedonism }\end{array}$ & "Seek pleasure and sensuous gratification" \\
Self-enhancement & "Seek personal success" & Read articles about the work \\
Self-transcendence & "Show concern for the welfare and interests of others" & Read articles about the environment \\
\hline
\end{tabular}

Finally, we formed the trait-based questions (Table 1) using the rules the specifications of which based on the denotations of the IBM Natural Language Understanding service. Although, our rules generate some grammatical issues (e.g., am aware instead of 'am I aware'), the results remain recognizable. Further, we realized that the definitions of the needs and values follow our rules. However, the explanations of the facets are transformed into the question format. Instead of the summary, the traits and their definitions or explanations offer the starting point for the discussions during the interventions. Therefore, the tables are useful to interpret the results of the IBM Watson Personality Insights service. Furthermore, 47 traits open the features of the human being and they even explain the constraints for collaboration of different kind.

\section{Discussion}

The cognitive services can be consciously used decrease the human interventions if the argumentations of the cognitive services are acceptable. Therefore, the argumentation is needed, i.e., how extractions (e.g., emotions, language styles, social tendencies, needs and values) can be explained, or even reached, through logical reasoning. The intentional and unintentional experiences of the authors affect the linguistic of which can be indicated (e.g., whether the sentences are analytical, confident or tentative). Moreover, the research background of the cognitive services has to be explicitly figured out when the cognitive services and their applications are used to predict behavioral outcomes and to provide recommendations.
The cognitive services can accumulate our cognition. For example, we can extract the tones (i.e., emotions, language styles and social tendencies) and personality traits (i.e., social tendencies and their facets, needs and values) from a web-site document with no time. We can use the outcomes (e.g., tones) to revise our text or we will use the facilitated denotations (e.g., semantic roles).

Usually, when we talk about the personality traits (e.g., social tendencies, needs and values) then we trust the ground-truth data without knowing that the inferred insights are more detailed ones. Traditionally, the personality traits are surveyed to get the ground-truth data (e.g., IPIP). Despite the lack of the studies to constitute the heritable nature (i.e., the modes of gene action) of each personality trait, the traits should be taken into to consideration during interventions, as well as, in preventive operations.

Before the professionals such as psychotherapists bring the IBM Personality Insights service into use, the functionality of the algorithm has to be verified together with substance professionals. Furthermore, more research has to be done to conduct the behavioral outcomes within the personality traits. However, the IBM Personality Insights service can be used within the interventions. Our established tables of the traits can be use when the results of the Personality Insights service are interpreted.

The inferred personality traits are the evidence-based (i.e., spoken or written text) insights of the consciousness of the human being. The intentional and unintentional experiences affect the consciousness of the human being the degree, clarity and linguistic of which can 
be indicated. In future, we will get the non-repudiation data through the gene tests. Hence, the inferred personality traits can be used to predict the behavioral outcomes.

\section{References}

[1] IBM. Watson services [cited 2017 Mar 30]. Available from: http://www.ibm.com/watson/developercloud/ services-catalog.html

[2] Microsoft. Discover API's [cited 2017 Mar 30]. Available from: https://www.microsoft.com/cognitiveservices/en-us/apis

[3] IBM. How precise is the service [cited 2017 Mar 30] Available from: http://www.ibm.com/watson/ developercloud/doc/personality-

insights/science.shtml\#researchPrecise

[4] IBM. Consumption preferences [cited 2017 Mar 30]. Available from: http://www.ibm.com/watson/ developercloud/doc/personality-

insights/preferences.shtml

[5] Hotti V, Gain U. Big Data Analytics for Professionals, Data-milling for Laypeople. World Journal of Computer Application and Technology, 2013;1(2);51-57.

[6] Hotti V, Gain U, Lintula H, Puumalainen A, Salomaa $\mathrm{H}$. Construction of business-driven capta processing. Advanced Research in Scientific Areas, EDIS - Publishing Institution of the University of Zilina. 2014;3(1).

[7] Hotti V. Sisällön tulkinta haastaa big datan louhijat. Futura. 2016;2:70-9.

[8] Hotti V, Gain U. Exploitation and exploration underpin business and insights underpin business analytics. 6th International Conference on Well-Being in the Information Society, 2016, p. 223-37.

[9] IBM. Use cases [cited 2017 Mar 30]. Available from: http://www.ibm.com/smarterplanet/us/en/ibmwatson /developercloud/doc/personalityinsights/usecases.shtml

[10] IBM. Personality Insights [cited 2017 Mar 30]. Available from: https://www.ibm.com/watson/ developercloud/personality-insights.html
[11] IBM. Tone Analyzer [cited 2017 Mar 30]. Available from: https://www.ibm.com/watson/developercloud/ tone-analyzer.html

[12] Vorhies W. 30 Fun Ideas for Starting New Al Businesses and Services with Watson, [cited 2017 Mar 30]. Available from: http://www.datasciencecentral.com/ profiles/blogs/30-fun-ideas-for-starting-new-aibusinesses-and-services-with-wat

[13] van den Berg SM., de Moor MHM, Verweij KJH, Krueger RF, Luciano M, Vasquez AA, et al. Meta-analysis of Genome-Wide Association Studies for Extraversion: Findings from the Genetics of Personality Consortium. Behavior Genetics. 2016;46(2):170-82. https://doi.org/10.1007/s10519-015-9735-5

[14] The Open Group. TOGAF, Content Metamodel [cited 2017 Mar 30]. Available from: http://pubs.opengroup.org/architecture/togaf9doc/arch/chap34.html\#tag_34

[15] Microsoft. Text Analytics API [cited 2017 Mar 30]. Available from: https://www.microsoft.com/cognitiveservices/en-us/text-analytics-api

[16] IBM. Personality Insights [cited 2017 Mar 30]. Available from: https://www.ibm.com/watson/ developercloud/doc/personality-

insights/output.shtml\#numeric

[17] The International Personality Item Pool. IPIP [cited 2017 Mar 30]. Available from: http://ipip.ori.org/ newScoringInstructions.htm

[18] IBM. Natural Language Understanding [cited 2017 Mar 30]. Available from: https://www.ibm.com/ watson/developercloud/natural-languageunderstanding.html

[19] IBM. Emotional tone [cited 2017 Mar 30]. Available from: http://www.ibm.com/watson/developercloud/ doc/tone-analyzer/understand-tone.html\#emotionaltone

[20] IBM. Personality Insights basics [cited 2017 Mar 30]. Available from: http://www.ibm.com/watson/ developercloud/doc/personality-insights/basics.shtml

[21] IBM. Big Five Personality Dimensions: Characteristics of Individuals with High- and Low-Value Combina- 
tions of Dimensions [cited 2017 Mar 30]. Available from: https://github.com/watson-developer-cloud/doctutorial-downloads/raw/master/personalityinsights/Personality-Insights-Dimension-

Characteristics.pdf

[22] IBM. Personality models [cited 2017 Mar 30]. Available from: https://www.ibm.com/watson/ developercloud/doc/personality-insights/models.shtml
[23] IBM. The service in action [cited 2017 Mar 30]. Available from: http://www.ibm.com/watson/ developercloud/doc/personality-insights/applied.shtml

[24] IBM. Needs [cited 2017 Mar 30]. Available from: https://www.ibm.com/watson/developercloud/doc/per sonality-insights/models.shtml\#outputNeeds

[25] IBM. Values [cited 2017 Mar 30]. Available from: http://www.ibm.com/watson/developercloud/doc/pers onality-insights/models.shtml\#outputValues 
Appendix 1. Dimensions and IPIP questions, as well as, the scores of the answers.

$\mathrm{O}=$ Openness, $\mathrm{C}=$ Conscientiousness, $\mathrm{E}=$ Extraversion, $\mathrm{A}=$ Agreeableness, $\mathrm{E}=$ Emotional Range, $\# \mathrm{Q}=$ Number of Questions, $\mathrm{VEI}=$ Very inaccurate, $\mathrm{MOI}=$ Moderately inaccurate, INA=Neither inaccurate not accurate,MOA=Moderately accurate, $\mathrm{VEA}=$ Very accurate.

\begin{tabular}{|c|c|c|c|c|c|c|c|c|c|c|c|}
\hline 0 & C & $\mathbf{E}$ & A & ER & $\# \mathbf{Q}$ & Cited ITIP questions [17] & VEI & MOI & INA & MOA & VEA \\
\hline & & $x$ & & & 6. & Don't talk a lot. & 1 & 2 & 3 & 4 & 5 \\
\hline & & $x$ & & & 16. & Keep in the background. & 1 & 2 & 3 & 4 & 5 \\
\hline & & $x$ & & & 26. & Have little to say. & 1 & 2 & 3 & 4 & 5 \\
\hline & & $x$ & & & 36. & Don't like to draw attention to myself. & 1 & 2 & 3 & 4 & 5 \\
\hline & & $x$ & & & 46. & Am quiet around strangers. & 1 & 2 & 3 & 4 & 5 \\
\hline & & $x$ & & & 1. & Am the life of the party. & 5 & 4 & 3 & 2 & 1 \\
\hline & & $x$ & & & 11. & Feel comfortable around people. & 5 & 4 & 3 & 2 & 1 \\
\hline & & $x$ & & & 21. & Start conversations. & 5 & 4 & 3 & 2 & 1 \\
\hline & & $x$ & & & 31. & Talk to a lot of different people at parties. & 5 & 4 & 3 & 2 & 1 \\
\hline & & $x$ & & & 41. & Don't mind being the center of attention. & 5 & 4 & 3 & 2 & 1 \\
\hline & & & $x$ & & 2. & Feel little concern for others. & 1 & 2 & 3 & 4 & 5 \\
\hline & & & $x$ & & 12. & Insult people. & 1 & 2 & 3 & 4 & 5 \\
\hline & & & $x$ & & 22. & Am not interested in other people's problems. & 1 & 2 & 3 & 4 & 5 \\
\hline & & & $x$ & & 32. & Am not really interested in others. & 1 & 2 & 3 & 4 & 5 \\
\hline & & & $x$ & & 7. & Am interested in people. & 5 & 4 & 3 & 2 & 1 \\
\hline & & & $x$ & & 17. & Sympathize with others' feelings. & 5 & 4 & 3 & 2 & 1 \\
\hline & & & $x$ & & 27. & Have a soft heart. & 5 & 4 & 3 & 2 & 1 \\
\hline & & & $x$ & & 37. & Take time out for others. & 5 & 4 & 3 & 2 & 1 \\
\hline & & & $x$ & & 42. & Feel others' emotions. & 5 & 4 & 3 & 2 & 1 \\
\hline & & & $x$ & & 47. & Make people feel at ease. & 5 & 4 & 3 & 2 & 1 \\
\hline & $x$ & & & & 8. & Leave my belongings around. & 1 & 2 & 3 & 4 & 5 \\
\hline & $x$ & & & & 18. & Make a mess of things. & 1 & 2 & 3 & 4 & 5 \\
\hline & $x$ & & & & 28. & Often forget to put things back in their proper place. & 1 & 2 & 3 & 4 & 5 \\
\hline & $x$ & & & & 38. & Shirk my duties. & 1 & 2 & 3 & 4 & 5 \\
\hline & $x$ & & & & 3. & Am always prepared. & 5 & 4 & 3 & 2 & 1 \\
\hline & $x$ & & & & 13. & Pay attention to details. & 5 & 4 & 3 & 2 & 1 \\
\hline & $x$ & & & & 23. & Get chores done right away. & 5 & 4 & 3 & 2 & 1 \\
\hline & $x$ & & & & 33. & Like order. & 5 & 4 & 3 & 2 & 1 \\
\hline & $x$ & & & & 43. & Follow a schedule. & 5 & 4 & 3 & 2 & 1 \\
\hline & $x$ & & & & 48. & Am exacting in my work. & 5 & 4 & 3 & 2 & 1 \\
\hline & & & & $x$ & 4. & Get stressed out easily. & 1 & 2 & 3 & 4 & 5 \\
\hline & & & & $x$ & 14. & Worry about things. & 1 & 2 & 3 & 4 & 5 \\
\hline & & & & $x$ & 24. & Am easily disturbed. & 1 & 2 & 3 & 4 & 5 \\
\hline & & & & $x$ & 29. & Get upset easily. & 1 & 2 & 3 & 4 & 5 \\
\hline & & & & $x$ & 34. & Change my mood a lot. & 1 & 2 & 3 & 4 & 5 \\
\hline & & & & $x$ & 39. & Have frequent mood swings. & 1 & 2 & 3 & 4 & 5 \\
\hline & & & & $x$ & 44. & Get irritated easily. & 1 & 2 & 3 & 4 & 5 \\
\hline & & & & $x$ & 49. & Often feel blue. & 1 & 2 & 3 & 4 & 5 \\
\hline & & & & $x$ & 9. & Am relaxed most of the time. & 5 & 4 & 3 & 2 & 1 \\
\hline & & & & $x$ & 19. & Seldom feel blue. & 5 & 4 & 3 & 2 & 1 \\
\hline$x$ & & & & & 10. & Have difficulty understanding abstract ideas. & 1 & 2 & 3 & 4 & 5 \\
\hline$x$ & & & & & 20. & Am not interested in abstract ideas. & 1 & 2 & 3 & 4 & 5 \\
\hline$x$ & & & & & 30. & Do not have a good imagination. & 1 & 2 & 3 & 4 & 5 \\
\hline$x$ & & & & & 5. & Have a rich vocabulary. & 5 & 4 & 3 & 2 & 1 \\
\hline$x$ & & & & & 15. & Have a vivid imagination. & 5 & 4 & 3 & 2 & 1 \\
\hline$x$ & & & & & 25. & Have excellent ideas. & 5 & 4 & 3 & 2 & 1 \\
\hline$x$ & & & & & 35. & Am quick to understand things. & 5 & 4 & 3 & 2 & 1 \\
\hline$x$ & & & & & 40. & Use difficult words. & 5 & 4 & 3 & 2 & 1 \\
\hline$x$ & & & & & 45. & Spend time reflecting on things. & 5 & 4 & 3 & 2 & 1 \\
\hline$x$ & & & & & 50. & Am full of ideas. & 5 & 4 & 3 & 2 & 1 \\
\hline
\end{tabular}


Appendix 2. Personality traits. Facets the explanations of which are adapted [10].

\begin{tabular}{|c|c|c|}
\hline Facet / trait & High explanation & Low explanation \\
\hline Adventurousness & $\begin{array}{l}\text { Adventurous: "You are eager to experience new } \\
\text { things" }\end{array}$ & $\begin{array}{l}\text { Consistent: "You enjoy familiar routines and prefer not to } \\
\text { deviate from them" }\end{array}$ \\
\hline Artistic interests & $\begin{array}{l}\text { Appreciative of art: "You enjoy beauty and seek out } \\
\text { creative experiences" }\end{array}$ & $\begin{array}{l}\text { Unconcerned with art: "You are less concerned with artistic or } \\
\text { creative activities than most people" }\end{array}$ \\
\hline Emotionality & $\begin{array}{l}\text { Emotionally aware: "You are aware of your feelings } \\
\text { and how to express them" }\end{array}$ & $\begin{array}{l}\text { Dispassionate: "You do not frequently think about or openly } \\
\text { express your emotions" }\end{array}$ \\
\hline Imagination & Imaginative: "You have a wild imagination" & Down-to-earth: "You prefer facts over fantasy" \\
\hline Intellect & $\begin{array}{l}\text { Philosophical: "You are open to and intrigued by new } \\
\text { ideas and love to explore them" }\end{array}$ & $\begin{array}{l}\text { Concrete: "You prefer dealing with the world as it is, rarely } \\
\text { considering abstract ideas" }\end{array}$ \\
\hline $\begin{array}{l}\text { Authority- } \\
\text { challenging }\end{array}$ & $\begin{array}{l}\text { Authority-challenging: "You prefer to challenge au- } \\
\text { thority and traditional values to effect change" }\end{array}$ & $\begin{array}{l}\text { Respectful of authority: "You prefer following with tradition to } \\
\text { maintain a sense of stability" }\end{array}$ \\
\hline $\begin{array}{l}\text { Achievement } \\
\text { striving }\end{array}$ & $\begin{array}{l}\text { Driven: "You set high goals for yourself and work hard } \\
\text { to achieve them" }\end{array}$ & $\begin{array}{l}\text { Content: "You are content with your level of accomplishment } \\
\text { and do not feel the need to set ambitious goals" }\end{array}$ \\
\hline Cautiousness & $\begin{array}{l}\text { Deliberate: "You carefully think through decisions } \\
\text { before making them" }\end{array}$ & $\begin{array}{l}\text { Bold: "You would rather take action immediately than spend } \\
\text { time deliberating making a decision" }\end{array}$ \\
\hline Dutifulness & $\begin{array}{l}\text { Dutiful: "You take rules and obligations seriously, even } \\
\text { when they are inconvenient" }\end{array}$ & $\begin{array}{l}\text { Carefree: "You do what you want, disregarding rules and } \\
\text { obligations" }\end{array}$ \\
\hline Orderliness & $\begin{array}{l}\text { Organized: "You feel a strong need for structure in } \\
\text { your life" }\end{array}$ & $\begin{array}{l}\text { Unstructured: "You do not make a lot of time for organization } \\
\text { in your daily life" }\end{array}$ \\
\hline Self-discipline & Persistent: "You can tackle and stick with tough tasks" & $\begin{array}{l}\text { Intermittent: "You have a hard time sticking with difficult tasks } \\
\text { for a long period of time" }\end{array}$ \\
\hline Self-efficacy & $\begin{array}{l}\text { Self-assured: "You feel you have the ability to succeed } \\
\text { in the tasks you set out to do" }\end{array}$ & $\begin{array}{l}\text { Self-doubting: "You frequently doubt your ability to achieve } \\
\text { your goals" }\end{array}$ \\
\hline Activity level & $\begin{array}{l}\text { Energetic: "You enjoy a fast-paced, busy schedule with } \\
\text { many activities" }\end{array}$ & Laid-back: "You appreciate a relaxed pace in life" \\
\hline Assertiveness & $\begin{array}{l}\text { Assertive: "You tend to speak up and take charge of } \\
\text { situations, and you are comfortable leading groups" }\end{array}$ & $\begin{array}{l}\text { Demure: "You prefer to listen than to talk, especially in group } \\
\text { situations" }\end{array}$ \\
\hline Cheerfulness & $\begin{array}{l}\text { Cheerful: "You are a joyful person and share that joy } \\
\text { with the world" }\end{array}$ & Solemn: "You are generally serious and do not joke much" \\
\hline $\begin{array}{l}\text { Excitement- } \\
\text { seeking }\end{array}$ & $\begin{array}{l}\text { Excitement-seeking: "You are excited by taking risks } \\
\text { and feel bored without lots of action going on" }\end{array}$ & $\begin{array}{l}\text { Calm-seeking: "You prefer activities that are quiet, calm, and } \\
\text { safe" }\end{array}$ \\
\hline Outgoing & $\begin{array}{l}\text { Outgoing: "You make friends easily and feel comforta- } \\
\text { ble around other people" }\end{array}$ & $\begin{array}{l}\text { Reserved: "You are a private person and do not let many } \\
\text { people in" }\end{array}$ \\
\hline Gregariousness & Sociable: "You enjoy being in the company of others" & $\begin{array}{l}\text { Independent: "You have a strong desire to have time to your- } \\
\text { self" }\end{array}$ \\
\hline Altruism & $\begin{array}{l}\text { Altruistic: "You feel fulfilled when helping others and } \\
\text { will go out of your way to do so" }\end{array}$ & $\begin{array}{l}\text { Self-focused: "You are more concerned with taking care of } \\
\text { yourself than taking time for others" }\end{array}$ \\
\hline Cooperation & $\begin{array}{l}\text { Accommodating: "You are easy to please and try to } \\
\text { avoid confrontation" }\end{array}$ & Contrary: "You do not shy away from contradicting others" \\
\hline Modesty & $\begin{array}{l}\text { Modest: "You are uncomfortable being the center of } \\
\text { attention" }\end{array}$ & $\begin{array}{l}\text { Proud: "You hold yourself in high regard and are satisfied with } \\
\text { who you are" }\end{array}$ \\
\hline Uncompromising & $\begin{array}{l}\text { Uncompromising: "You think it is wrong to take ad- } \\
\text { vantage of others to get ahead" }\end{array}$ & $\begin{array}{l}\text { Compromising: "You are comfortable using every trick in the } \\
\text { book to get what you want" }\end{array}$ \\
\hline Sympathy & $\begin{array}{l}\text { Empathetic: "You feel what others feel and are com- } \\
\text { passionate toward them" }\end{array}$ & $\begin{array}{l}\text { Hard-hearted: "You think people should generally rely more on } \\
\text { themselves than on others" }\end{array}$ \\
\hline Trust & $\begin{array}{l}\text { Trusting of others: "You believe the best in others and } \\
\text { trust people easily" }\end{array}$ & $\begin{array}{l}\text { Cautious of others: "You are wary of other people's intentions } \\
\text { and do not trust easily" }\end{array}$ \\
\hline Fiery & $\begin{array}{l}\text { Fiery: "You have a fiery temper, especially when things } \\
\text { do not go your way" }\end{array}$ & Mild-tempered: "It takes a lot to get you angry" \\
\hline Prone to worry & $\begin{array}{l}\text { Prone to worry: "You tend to worry about things that } \\
\text { might happen" }\end{array}$ & Self-assured: "You tend to feel calm and self-assured" \\
\hline Melancholy & $\begin{array}{l}\text { Melancholy: "You think quite often about the things } \\
\text { you are unhappy about" }\end{array}$ & $\begin{array}{l}\text { Content: "You are generally comfortable with yourself as you } \\
\text { are" }\end{array}$ \\
\hline Immoderation & $\begin{array}{l}\text { Hedonistic: "You feel your desires strongly and are } \\
\text { easily tempted by them" }\end{array}$ & $\begin{array}{l}\text { Self-controlled: "You have control over your desires, which are } \\
\text { not particularly intense" }\end{array}$ \\
\hline $\begin{array}{l}\text { Self- } \\
\text { consciousness }\end{array}$ & $\begin{array}{l}\text { Self-conscious: "You are sensitive about what others } \\
\text { might be thinking of you" }\end{array}$ & $\begin{array}{l}\text { Confident: "You are hard to embarrass and are self-confident } \\
\text { most of the time" }\end{array}$ \\
\hline $\begin{array}{l}\text { Susceptible to } \\
\text { stress }\end{array}$ & $\begin{array}{l}\text { Susceptible to stress: "You are easily overwhelmed in } \\
\text { stressful situations" }\end{array}$ & $\begin{array}{l}\text { Calm under pressure: "You handle unexpected events calmly } \\
\text { and effectively" }\end{array}$ \\
\hline
\end{tabular}

